\title{
Workforce development for harnessing light
}

\section{Robert Breault}

Robert P. Breault, "Workforce development for harnessing light," Proc. SPIE 3831, Sixth International Conference on Education and Training in Optics and Photonics, (16 June 2000); doi: 10.1117/12.388734

Event: Education and Training in Optics and Photonics (ETOP'99), 1999, Cancun, Mexico 


\title{
Workforce Development for Harnessing Light
}

\author{
Robert Breault \\ Breault Research Organization, Inc \\ Arizona Optics Industry Association \\ Tucson, Arizona 85715 \\ 520-721-0500 Off \\ 520-721-9630 Fax \\ bbreault@breault.com
}

\begin{abstract}
The COSE report on Harnessing Light has had a global impact. This paper addresses a not-too-distant opportunity for the emerging nations around the world that have the courage and foresight to dramatically change their approach to economic development. It is a challenge to the private sector of the optics/photonics around the world. It is a call to them to stretch out and try to grab a piece of the rich commercial markets in optics and photonics that the traditional countries (the Europeans, Japanese, and US) around the world will not be able to service. I talk about a revolution in and by the small, medium, and yet to be companies. There will be far more demand by the commercial optical markets than these traditional countries will be able to service. The field of photonics and optics is quickly maturing in a very natural and predictable but revolutionary manner. In the last two years many more people recognize and appreciate the current evolutionary state of the optics markets, and have some idea of their economic size. The emphasis now needs to be on workforce development.
\end{abstract}

KEYWORDS: Optics, photonics, education, workforce development

\section{INTRODUCTION}

Two years ago I presented a paper at the Fifth International Topical Meeting on Education and Training in Optics named Meeting The Calculated Market Needs For Optically Trained Physicists, Engineers, And Technicians In 2005. In that paper I expressed my concern about the pending explosive growth of the optics industry and our own global inability to meet the demands of workforce creation and development, the lack planning at the regional and national levels, the lack of knowledge and understanding of the new economic forces, and organization in general. I expressed my concern that the optics industry would "eat its seed corn", i.e. lure the professors away from their teaching profession at the few optical sciences centers around the world into industry with handsome salaries and equity. The very professors that industry needs to do the teaching, and training of optical physicists and engineers that our industry needs in increasing numbers.

\section{ECONIMIC FORCASTS}

The current estimated size of the global market for just the photonics industry is about $\$ 50$ billion, growing to $\$ 500$ billion by the year 2010. I sense that that is under-estimated and conservative, just like industry has underestimated the personal computer industry size and growth, and we have underestimated the laser and fiber market industries to name a few. How much higher this number will be is only a guess at this time. We are talking about a growth factor of 10 or more in the next twelve years. If one assumes it takes an average of about five years to get a $\mathrm{Ph} . \mathrm{D}$. and then a few years to establish oneself, we are faced with the problem that there are not enough students in the system to support the growth. In fact there are not enough educational departments with trained staff to educate students if they wanted to register. We are going to have to solve the "problem" differently. And by "we" I am putting the challenge to the public sector, business and academics to play a major role in economic development. We have a poor track record at being active collaborative participants in the past. In many cases the expression that could be used is "it is not my job, nor my desire to be involved". We have been apathetic in our response to the growth of our own industry. We have been and are reluctant to create "vocational" schools for technicians. 


\section{CHANGES}

Since that short time ago the optics industry has grown exponentially and we are doing just that. We are hiring the professors; we are hiring students before they get their advanced degrees. Two years ago there were three Optics Clusters in North America. At this time there are eleven, and more in the making. There are some overseas and others that are considering Clusters. Typical corporate membership participation in Optics Clusters has tripled. Cluster gross revenue is estimated to have at least doubled. The Coalition for Photonics and Optics (COSE) have come out with "the COSE" study on the industry, Harnessing Light that certifies that optics is the enabling industry of the $21^{\text {st }}$ century. Trillion dollar industries depend on optics. I now commend then for all of us on their long but successful effort. I know that many competitive nations outside the US have latched onto the report and are using it extensively to promote the optics industry in their countries. This is a prime example where a competitor can do more good for you that all the combined other efforts of a region. It has galvanized the global optics community in a positive way. Harnessing Light is an in depth study confirming the global economic importance of the optics and/or photonics industry. Harnessing Light is not the complete story. Great as it is it has missed some important areas and does not discuss the concept of competition.

Since the 1997 meeting in Delft unemployment in the US has dropped dramatically (as predicted by Charles Handy, Age of Unreason, 1989). It is looked upon with envy by most as a blessing. Unemployment nationally is in the $4 \%$ range, while in some areas such as Tucson it has gone down to $2.3 \%$ and in Minneapolis down to just $1.3 \%$. With more people working the US now has a balanced budget, really a surplus, and has the potential of paying off its astronomical national debt in the next ten years. It is not looked upon as a pending catastrophe. The current difficulty in hiring qualified employees is thought of as a temporary sign of the times, the side effect of a temporary strong economy. Many optics companies could produce and sell more if they had the manpower. I will point out that in these glory days the seeds of a future disaster have already taken root.

\section{OPPORTUNITY TODAY}

Some enlightened countries have their sights on specific sectors of the industry and are investing heavily, some are just entering with great expectations, and other countries are just not in the chase. However, a few national programs have come to the realization that there will not be enough trained personnel in the traditional countries to meet the market demand. Education, a fairly higher degree of education than most past technical disciplines, is the key to the success of any future hot spot, hot region, of commercial value. Few recognize that this has created a significant opportunity for their countries, or regions of a country, to enter into the higher levels of the economic food train, the high paying value added type of jobs. The traditional countries, the US included, do not recognize that the barrier to entry is gone, hence the barrier to market entry is open to all who are willing to change. While many emerging countries look on in envy of the US economy right (1998-99) now they are oblivious of the best opportunity their nations have ever had to seize a significant portion of global markets. The high end of the global markets, the knowledge based service industries with higher wages. In some sense it could be very easy to garner some significant portion of this market. It has been there for the taking for a long time. Japan long ago recognized the economic opportunity of optical disk storage, flat screen displays, and the medical markets in optics. Taiwan and Scotland are current day exceptions where they too have planned and aggressively are carrying out their plans to seize significant global market shares of the optics and photonics industries. Singapore too thinks that it has found the message.

To some degree they are right, but in the most significant ways they haven't gotten the message, or are so cleaver that they have but are intentionally showing no signs that they have. While the world now knows that the money in the optics' related markets is real, and will be so well into the $21^{\text {st }}$ century, they all are missing the workforce development issue. There are not enough unemployed qualified workers in the US and it is going to get steadily worse over the next 15 years! There are a few studies that show that as the baby boomers move out of the workforce over the next 15 years the replacement force is dramatically less, dramatically less. The labor shortage will get worse in the US. There were not enough babies born between 1995 and 1999 to replace the baby boomers who will retire. For the next twenty years the cumulative knowledge retiring from the field (related to but not exactly the same as the number of people) will exceed the cumulative knowledge entering the field. Let me try to explain. Right now there are many senior and experienced managers who are "carrying" more than a normal share of "employees in training". These managers are good. They have a lot of experienced. They are seeded. The next generation of managers will have to manage and carry more responsibility as the market expands and they will have less experience and even fewer resources to draw upon. 


\section{TIME FOR A REBELLION}

Part of the solution that I advocate is a rebellion, a full-scale rebellion against the established big companies, against the government's traditional economic development policies, even the past great ones. While I know that those words could be a criminal offense in many of the nations that I am trying to reach out to, or even in the US, it is not only what not should take place, but will take place. It will only be a matter of time. Money has "a mind of its own". Big sums of money will eventually motivate the industry and students looking for careers. Those who move intelligently first and the fastest will be the winners and all others will be also rans. Since governments are not noted for moving fast, nor for being early adapters of new economic models, this revolution will have to be driven by industry. But then even big companies are not noted for reinventing themselves. Therefore this revolution will come from the small medium sized companies. But for that to happen in many regions of the world their governments are going to have to understand the new opportunities and develop the necessary infrastructure to support entrepreneurship. Some will never respond in time.

\section{VALUE ADDED, KNOWLEDGE BASED, QUALITY PAY JOBS The US Baby Boomer Era Ramifications}

Today emerging nations can get on the gravy train of the high side of economic growth and wealth. The real stuff. It is partially due to the cities like Tucson and Minneapolis where they have enjoyed a net gain in in-migration of approximately 20,000 people per year for the last 40 years. A study of Minneapolis's current and future workforce revealed that this number will dramatically drop to about 2,000 people by the middle or end of the second decade in the $21^{\text {st }}$ century. For a city that currently employs $80 \%$ of all its citizens over 20 years old, regardless of health or physical condition and handicaps, this is a clear warning that their economy will have to change. They have taken workforce development as their major economic issue. To them workforce development is no longer job creation. To them, workforce development is the education, training and skill development of all their laborers at all-cultural backgrounds, both sexes, and at all economic levels. They will no longer be able to squander the brainpower of any citizen. Currently they have 14,000 jobs open at the $\$ 40,000 / y e a r$ pay scale. They have run out of people, and they know that it is going to get worse if they do not do something about it.

The real problem is that the die is cast. We cannot create a host of five-year olds in this coming year. It is no longer that there might be a problem, but rather that there is a problem for the US. It will also occur in other regions of the world but timing will not be coincident. The current workforce demand in the US is so strong that the industries have convinced the US government to temporarily nearly double the number of foreigners allowed to enter the US for work, N1D Visas. By June of 1999 we have filled the allotted quota. To most this is seen as a temporary stopgap measure and not a sign of a permanent need. It will take a radical change of mind in too many legislators before they seriously contemplate that the economic welfare of the nation is dependent on far more than 100,000 new qualified immigrants per year.

It is well known that the US industries have been dramatically losing its manufacturing base to oversea nations. Nevertheless the US economy is booming! The US has turned to the service industries, the value added upside of today's' economy. Knowledge is what is being sold. But in today's world knowledge is mobile. Knowledge and money are much more mobile than in any other time of history. Visionary plans and brilliant breakthroughs are not enough. Money still makes things happen. The secret is how to bring the two together. I see part of the solution in the pure accumulation of knowledge in a fairly small region. The pool of knowledge has been shown to create competitiveness and new technologies, or new methods that introduce disruptive technologies that replace even the most well established markets in the world. The current global markets are dramatically different in the 1990's than they were through out the rest of this century. The global market is not just some expanded geographical market region where a company can find new customers. Companies have been doing that for years. Now there are global partners not just global customers. The big money making successful companies have no problem with laying off manufacturing laborers when they can find less expensive laborers overseas. They may not be as efficient or as productive relative to their American counterpart but they have proven themselves to be cost effective.

Let us go back in time to the most primitive form of an economy, the barter system. In those days if you had something another person wanted you would be offered something that you might want more than what you now processed, or could make. You made value decisions to give up item A for item B. I assume there is no war like attitude of pure taking the item away. Who gains wealth in the deal is determined by the productivity of the maker of each item made and their perceived value as an item of pleasure (excess capital) or need. Both if concept could find the deal profitable. The US will need, if fact now needs, what other countries have - trained people. Other regions now have trained workforces for the manufacturing 
industries. The US now needs a highly trained workforce for the value-added jobs. That market is now open. It can be serviced by a brain drain, or it can be serviced as in a partnership if a region is willing to compete for its own workforce, its own people, its own resource. To do that any region in the world, in any country, must compete on quality of life issues. That means the whole spectrum. It means a good and supportive political system, a good educational system for the employees and their family, opportunities for upward mobility of the employee and their children. It is a region without war, without fear, with a safe envirnment in every sense of the word. It also needs the necessary inrastructure; telscommunications being high on the list; air transportation also.

The US is entering a time of imbalance between its opportunities and its ability to capitalize on these opportunities. Even now in the optics industry there are far more lucrative markets than there are resources to capture them. Many industries have put many solid ideas on a back burner because of a lack of trained manpower.

The science and physics of light, as we all recognize is an $\mathrm{E}^{3}$ technology; it services Emerging technologies, Enhances existing technologies, and helps existing technologies Evolve. The problem is here now!

But there are many parts, and like any good symphony, all the players need to be informed and in tune.

\section{Structure: A Region needs a coordinated plan for the $21^{\text {st }}$ century.}

Any region that wants a significant share of the knowledge based global economic opportunities needs a coordinated plan for the $21^{\text {st }}$ century, or as some like to say, "the Age of Enlightenment". I think that it is safe to assume that we each love our science and love doing it. I suggest a global effort be made between the academics, the industrialists, and the public sector, yes across borders, to develop a strategy to promote careers in the field of optics at all levels of education, promote the opportunities of such careers, create a "standard", a certification of various levels of accomplishment. We need to educate our public sector as to the economic opportunities of our industry, and support surveys and market analysis of our industry so that investors of all sorts can find market data in our field. Today it does not exist. Today it takes yet another leap of faith by the investors to invest in some new technology in our field. There is more than enough to go around, $\$ 500$ billion dollars. We should create a global awareness of the current market size and products used daily that requires optics. Make the world more aware of the industry and its future size, so that investors will put more money into the technology, and governments will support Research and Development and education. Educate our communities that we are not just perceived as being only about eyeglasses and telescopes. Educate our teachers, legislators at all levels.

I suggest a global effort be made between the academics, the industrials, students, the optics related societies, the members and participants of Coalition for Photonics and Optics (CPO), the International Commission for Optics (ICO), and the public sector of multiple nations, yes across borders, to develop a strategy to:

- promote careers in the field of optics at all levels of education,

- promote the opportunities of such careers,

- create a "standard", a certification of various levels of accomplishment,

- educate our public sector as to the economic opportunities of our industry, and for

- encourage industries to support surveys and market analyses of our industry so that investors of all sorts can find market data in our field. Today it does not exist.

\section{References}

C. Handy, THE Age OF UNREASON, Harvard Business School Press, 1989

National Research Council, Harnessing Light, Optical Science and Engineering for the $21^{\text {st }}$ Century, National Academy Press 1998.

Lester C. Thurow, Building Wealth, HarperCollins Publishers, 1999. 